\title{
Differences Between Urban and Rural Areas of the Republic of Suriname in the Ethnic and Age Distribution of Cancer - A Retrospective Study from 1980 Through 2004
}

\author{
D.R.A. Mans ${ }^{*}, 1$, E. Rijkaard ${ }^{1}$, J. Dollart ${ }^{1}$, G. Belgrave ${ }^{1}$, S.S. Tjin A Joe ${ }^{1}$, R. Matadin ${ }^{1}$, A. Algu ${ }^{1}$, \\ A.R.D. Hoeblal ${ }^{1}$, R. Kalloe ${ }^{1}$, Z. Nurmohamed ${ }^{1}$, R. Rampadarath ${ }^{1}$, R.N. Mohamedradja ${ }^{1}$, \\ A. Tewarie ${ }^{1}$, S. Sewgobin 1 , B. Ramautar ${ }^{1}$, A. Jagesar ${ }^{1}$, R. Mohan ${ }^{1}$, S. Adhin ${ }^{1}$, \\ R. Bansie ${ }^{1}$ and M.A. Vrede ${ }^{2}$
}

\author{
${ }^{I}$ Department of Pharmacology, Faculty of Medical Sciences, Anton de Kom University, Paramaribo, Suriname \\ ${ }^{2}$ Pathologic Anatomy Laboratory, Academic Hospital Paramaribo, Paramaribo, Suriname
}

\begin{abstract}
We investigated whether there were differences between the urban and rural areas of the Republic of Suriname with respect to the racial and age distribution of cancer between 1980 and 2004. Patient information was from the Pathologic Anatomy Laboratory, relevant population data from the General Bureau of Statistics. Urban and rural cancer incidence rates (means \pm SDs per 100,000 per year) were calculated for cancer overall as well as for the most common malignancies, and were stratified for the largest ethnic groups, viz. Creole, Hindustani, and Javanese, and for age strata 0-19, 20-49, and 50+ years. Rates for cancer overall and for most leading malignancies were up to 2.5 -fold higher in the urban areas than in the rural areas. Furthermore, rates for urban Creole were 1.5- to 5-fold higher than those for rural Creole as well as Hindustani and Javanese from either residence. Also, rates for urban individuals of 50+ years were approximately twice those for rural people of the same age group. These tendencies were most apparent for gastrointestinal, breast, hematological and prostate cancer. Our findings suggest that there were significant differences between the urban and rural areas of Suriname with respect to the ethnic and age distribution of cancer.
\end{abstract}

\section{INTRODUCTION}

The diversity in cancer incidence among different regions and populations, and different ethnic and age groups has been well-documented [1-3]. This phenomenon has been extensively used, among others, to formulate hypotheses to support relationships between cancer risk on the one hand, and genetic background as well as life-style and behavior on the other hand [1-3]. Examples of such relationships are the higher cancer incidence rates in densely inhabited, urbanized areas when compared to less populated, non-metropolitan areas $[4,5]$; the increased occurrence of malignancy in residents of a high-cancer incidence country who had migrated from a low-cancer incidence country when compared to that in residents from the country of origin [6-8]; and the higher frequency of prostate cancer and the higher levels of circulating androgens in African-American men when compared to males of other ethnic backgrounds [9].

The Republic of Suriname is located on the north-east coast of South America. Suriname's urban areas comprise the capital city of Paramaribo and the Wanica district, occupy $626 \mathrm{~km}^{2}$ of the country, and harbor approximately twothirds of the population of approximately 500,000 [10]. The remaining $163,194 \mathrm{~km}^{2}$ of the country's surface comprise the rural and interior parts which are divided in eight administrative districts [10]. The urban areas are characterized by a

*Address correspondence to this author at the Department of Pharmacology, Faculty of Medical Sciences, Anton de Kom University, Paramaribo, Suriname; E-mail: d.mans@uvs.edu 'western' life-style, modern health care facilities, and an economy based on commerce, services, and industry [10]. The rural societies have a more traditional way of living, lack comprehensive public health services, and have agriculture, forestry, as well as bauxite and gold mining as major economic activities [10].

The Surinamese population is among the most varied in the world, consisting of Hindustani (originating from India), Creole (mixed black and white), Javanese (originating from Java, Indonesia), Marroon (the descendants from runaway slaves shipped from Africa between the $16^{\text {th }}$ and the $19^{\text {th }}$ century), Amerindian (the original inhabitants) as well as immigrants from China, Lebanon, and various European countries [11]. The largest ethnic groups are the Hindustani, Creole, and Javanese, comprising approximately 27, 18, and $16 \%$, respectively, of the total population [11]. Although members of all ethnic groups are encountered throughout the country particularly in Paramaribo - certain ethnic groups are clustered in relatively large numbers in certain districts [11]. For example, the district of Nickerie harbors predominantly Hindustani, that of Para mostly Creole, and that of Commewijne mainly Javanese [11].

Taking into account the above-mentioned differences between Suriname's urban and rural areas, and considering the association of malignancy with environmental as well as genetic (i.e., racially-determined) factors, it is possible that both parts of the country also differ from each other with respect to the occurrence of (certain types of) cancer. So far, no studies on this topic have been carried out. Therefore, we 
assessed Suriname's urban and rural areas for possible differences in cancer incidence patterns for the period 19802004. The data obtained have been stratified according to ethnic background and age at the time of diagnosis.

\section{MATERIALS AND METHODS}

\section{Sources of Data}

In this study, the histopathologically confirmed malignant neoplasms registered in Suriname between January 1, 1980 and December 31, 2004 have been analyzed on the basis of urban or rural residence, and stratified according to ethnic background and age at the time of diagnosis. Benign lesions, in situ carcinomas, and non-melanoma skin cancers have been excluded from the study.

Relevant patient data were obtained from the pathologybased cancer registry managed by the Pathologic Anatomy Laboratory of the Academic Hospital Paramaribo. The Pathologic Anatomy Laboratory is the referral center for histopathological cancer diagnosis and cancer registration in Suriname, covers all histopathologically diagnosed cancers since the year 1960, and is generally regarded as Suriname's national cancer registry [12]. There is thus far no populationbased cancer registry in this country.

Cancer cases are classified using the International Classification of Diseases for Oncology, second edition [13], and include, among others, patients' name, gender, date and place of birth, ethnic origin, as well as address at the time of diagnosis. Per year, approximately three hundred new malignancies are registered at the Pathologic Anatomy Laboratory [14]. Reporting is estimated to be $90 \%$ complete [14]. Information about place of residence, ethnic background, and age of the patients is available for at least two-thirds of cases [14].

Population data, including estimates of the mid-year populations of the urban and rural administrative districts of Suriname for each year covered by this study, were provided by the Section Population Statistics of the General Bureau of Statistics residing under the Ministry of Planning and Devel- opmental Cooperation [11]. From these data, yearly midyear resident urban and rural population sizes were calculated.

\section{Data Analysis}

For each year between 1980 and 2004, numbers of overall cancer cases and numbers of the most common cancer types were determined for the urban and rural areas of Suriname for the three largest ethnic groups (Hindustani, Creole, and Javanese), and for cases aged between 0 and 19 years, between 20 and 49 years, and above 50 years. These age cut-offs were chosen in order to obtain strata that roughly reflect the juvenile and adolescent; the socioeconomically active; and the in general retired segments of the populations. Average yearly (crude) incidence rates were estimated by dividing the number of cancer cases for each group by the estimated mid-year resident urban or rural population, and were expressed per 100,000 urban or rural population. Data presented are means \pm SDs and have been compared using Student's $t$ test or ANOVA, taking $P$ values $<0.05$ to indicate statistically significant differences.

\section{RESULTS}

\section{Generalities}

There were approximately 7,500 cases of malignancy in Suriname in the period between January 1, 1980, and December 31, 2004. Information about the histopathology of the tumor, and relevant patient data were available for 6,095 patients, i.e., approximately $80 \%$ of cases. Only these cases have been included in the present survey.

A number of 4,743 patients, i.e., about three-quarters of the group included in the study, resided in the urban areas of Suriname, and 1,352 or about one-quarter in the rural areas (Table 1). The overall cancer incidence rate for the urban areas was $68 \pm 10$ per 100,000 per year, and that for the rural areas was $41 \pm 9$ per 100,000 per year (Table 1). Thus, cancer was roughly 1.5 times more common in the urban than in the rural areas of Suriname.

Table 1. Total Number of Cases, Average Yearly Numbers of Cases ( \pm SDs), and Average Yearly Incidence Rates $( \pm$ SDs) of Overall Cancer in Urban and Rural Areas of Suriname Between 1980 and 2004. Rates are Per 100,000 Urban or Rural Residents

\begin{tabular}{|l|c|c|c|c|c|c|}
\hline & \multicolumn{3}{|c|}{ Urban Areas } & \multicolumn{2}{c|}{ Rural Areas } \\
\cline { 2 - 7 } & $\begin{array}{c}\text { Number of } \\
\text { Cases }\end{array}$ & $\begin{array}{c}\text { Yearly Number of } \\
\text { Cases } \pm \text { SD }\end{array}$ & $\begin{array}{c}\text { Yearly Incidence } \\
\text { Rate } \pm \text { SD }\end{array}$ & $\begin{array}{c}\text { Number of } \\
\text { Cases }\end{array}$ & $\begin{array}{c}\text { Yearly Number of } \\
\text { Cases } \pm \text { SD }\end{array}$ & $\begin{array}{c}\text { Yearly Incidence } \\
\text { Rate } \pm \text { SD }\end{array}$ \\
\hline \hline Total & 4,743 & $190 \pm 37$ & $68 \pm 10^{1}$ & 1,352 & $54 \pm 13$ & $41 \pm 9$ \\
\hline Males & 2,003 & $80 \pm 23$ & $29 \pm 6^{2}$ & 517 & $21 \pm 6$ & $33 \pm 10$ \\
\hline Females & 2,738 & $110 \pm 18$ & $40 \pm 5^{2}$ & 833 & $25 \pm 7$ \\
\hline Hindustani & 908 & $36 \pm 8$ & $13 \pm 2$ & 350 & $14 \pm 5$ & $11 \pm 4$ \\
\hline Creole & 2,117 & $85 \pm 20$ & $30 \pm 6^{3}$ & 312 & $12 \pm 6$ & $14 \pm 4$ \\
\hline Javanese & 624 & $25 \pm 7$ & $9 \pm 2$ & 341 & $3 \pm 4$ \\
\hline $0-19$ years & 157 & $6 \pm 3$ & $2 \pm 1$ & 66 & $10 \pm 3$ \\
\hline $20-49$ years & 1,261 & $50 \pm 11$ & $18 \pm 4^{4}$ & 414 & $17 \pm 6$ \\
\hline $50+$ years & 3,240 & $130 \pm 29$ & $46 \pm 7^{4}$ & 821 & $33 \pm 10$ & $2 \pm 1$ \\
\hline
\end{tabular}

${ }^{1}$ Significantly different from rural areas $(P<0.001$, Student's $t$ test $) ;{ }^{2}$ significantly different from rural areas $(P<0.001$, Student's $t$ test $) ;{ }^{3}$ significantly different from Creole in rural areas as well as Hindustani and Javanese in urban and rural areas $\left(P<0.001\right.$, ANOVA); ${ }^{4}$ significantly different from rural areas $(P<0.001$, ANOVA $)$. 
Table 2. Total Number of Cases, Average Yearly Numbers of Cases ( \pm SDs), and Average Yearly Incidence Rates ( \pm SDs) of Common Cancers in Urban and Rural Areas of Suriname Between 1980 and 2004. Rates are Per 100,000 Urban or Rural Residents

\begin{tabular}{|c|c|c|c|c|c|c|}
\hline & \multicolumn{3}{|c|}{ Urban Areas } & \multicolumn{3}{|c|}{ Rural Areas } \\
\hline & $\begin{array}{l}\text { Number of } \\
\text { Cases }\end{array}$ & $\begin{array}{l}\text { Yearly Number of } \\
\text { Cases } \pm \text { SD }\end{array}$ & $\begin{array}{c}\text { Yearly Incidence } \\
\text { Rate } \pm \text { SD }\end{array}$ & $\begin{array}{l}\text { Number of } \\
\text { Cases }\end{array}$ & $\begin{array}{l}\text { Yearly Number of } \\
\text { Cases } \pm \text { SD }\end{array}$ & $\begin{array}{c}\text { Yearly Incidence } \\
\text { Rate } \pm \text { SD }\end{array}$ \\
\hline Cervix uteri & 824 & $33 \pm 6$ & $12 \pm 3$ & 314 & $13 \pm 5$ & $10 \pm 4$ \\
\hline Gastrointestinal tract & 732 & $29 \pm 5$ & $11 \pm 2^{1}$ & 172 & $7 \pm 3$ & $5 \pm 2$ \\
\hline Female breast & 656 & $26 \pm 7$ & $9 \pm 2^{1}$ & 135 & $5 \pm 3$ & $4 \pm 2$ \\
\hline Prostate & 526 & $21 \pm 15$ & $7 \pm 5^{1}$ & 112 & $4 \pm 3$ & $3 \pm 2$ \\
\hline Hematological system & 422 & $17 \pm 6$ & $6 \pm 2^{1}$ & 125 & $5 \pm 3$ & $4 \pm 2$ \\
\hline Head and neck & 323 & $13 \pm 6$ & $5 \pm 2$ & 112 & $4 \pm 3$ & $3 \pm 2$ \\
\hline Respiratory tract & 209 & $8 \pm 4$ & $3 \pm 2$ & 54 & $2 \pm 2$ & $2 \pm 1$ \\
\hline Liver & 129 & $5 \pm 3$ & $2 \pm 1$ & 67 & $3 \pm 2$ & $2 \pm 1$ \\
\hline
\end{tabular}

Significantly different from rural areas $(P<0.05$, Student's $t$ test $)$.

Table 2 shows the eight most common cancers in Suriname's urban and rural areas. These were, in urban as well as rural areas, cancer of the uterine cervix, gastrointestinal tract (esophagus, stomach, small bowel, colon, rectum, and anal canal), breast, hematological system, prostate, head and neck, respiratory tract (trachea, bronchus, lung, and pleura), and liver. Together, they comprised in both areas more than $80 \%$ of the total numbers of new cancers registered between 1980 and 2004.

Although there were more cases of cervical carcinoma in the urban areas than in the rural areas, incidence rates did not differ significantly from each other (Table 2). The same held true for the urban and rural cases of head and neck, respiratory tract, and liver cancer (Table 2). On the other hand, numbers of cases as well as incidence rates of malignancies of the gastrointestinal tract, breast, hematological system, and prostate were approximately twice higher in the urban areas than in the rural areas (Table 2). These findings are in accordance with the above-mentioned suggestion that cancer was more common in the urban than in the rural population.

There were approximately 1.5 times more female than male cases of cancer in the urban as well as rural areas (Table 1). This was probably attributable to the relatively high number of cervical and breast carcinoma patients in both areas (Table 2). More importantly, overall annual incidence rates for men and women in the urban areas $(29 \pm 6$ and $40 \pm$ 5 per 100,000 urban residents, respectively) were almost twice higher than those for men and women in the rural areas (16 \pm 4 and $25 \pm 7$ per 100,000 rural residents, respectively; Table 1). These observations also support the abovementioned suggestion that cancer occurred more frequently in the urban areas than in the rural areas of Suriname.

\section{Urban-rural Differences in the Racial Distribution of Cancer}

Most cancers (more than 2,100 of the total of 6,095 cases in the period covered by this study) were diagnosed in urban Creole (Table 1). The overall cancer incidence rate for this group ( $30 \pm 6$ per 100,000 population per year; Table 1) was almost three times that for rural Creole $(9 \pm 4$; Table 1) as well as those for both urban and rural Hindustani (13 \pm 2 and
$11 \pm 4$, respectively; Table 1) and both urban and rural Javanese ( $9 \pm 2$ and $10 \pm 3$, respectively; Table 1). Apparently, cancer manifested significantly more often in urban Creole than in rural Creole as well as Hindustani and Javanese of either residence, with no significant or only slight differences among the latter groups.

Tables 3a and 3b show that most leading cancer types were also more frequently diagnosed in urban Creole than in urban Hindustani, urban Javanese, and rural individuals from either ethnic origin, with no significant or only small differences in incidence rates among the latter groups. The apparent preference of malignant disease for urban Creole was clearest for common malignancies such as cancer of the gastrointestinal tract, breast, hematological system, and prostate (Tables 3a and 3b).

Again, cervical cancer, and probably also head and neck, respiratory tract, and liver cancer were the exceptions, the incidence rates for urban Creole not differing significantly or only very little from those for rural Creole and urban as well as rural Hindustani, and Javanese (Tables 3a and 3b). Despite this, the above-mentioned data provide strong indications for the existence of urban-rural differences with respect to the racial distribution of cancer in Suriname.

\section{Urban-Rural Differences in the Age Distribution of Can- cer}

The occurrence of cancer was in both urban and rural areas clearly age-dependent. Overall incidence rates increased in both regions readily with increasing age, i.e., from $2 \pm 1$ in age group 0-19 years to more than 5 and more than 10 times higher values in the age groups between 20 and 49 years, and of 50 years and older, respectively (Table 1). The difference in overall incidence rate between urban and rural individuals aged 20-49 years was relatively small (18 $\pm 4 v s$ $13 \pm 5$, respectively), but that between urban and rural individuals of 50 years and older was much more pronounced (46 \pm 7 vs $25 \pm 6$, respectively). This suggests that cancer was more often diagnosed in older urban individuals than in older rural people.

The data given in Tables $\mathbf{4 a}$ and $\mathbf{4 b}$ are in accordance with this assumption. The incidence rates of most leading 
Table 3a. Total Number of Cases and Average Yearly Incidence Rates ( \pm SDs) of Common Cancers in Hindustani, Creole, and Javanese in Urban Areas of Suriname Between 1980 and 2004. Rates are Per 100,000 Urban Residents

\begin{tabular}{|l|c|c|c|c|c|c|}
\hline & \multicolumn{2}{|c|}{ Hindustani } & \multicolumn{2}{c|}{ Creole } & \multicolumn{2}{c|}{ Javanese } \\
\cline { 2 - 7 } & $\begin{array}{c}\text { Total Number } \\
\text { of Cases }\end{array}$ & $\begin{array}{c}\text { Yearly Incidence } \\
\text { Rate } \pm \text { SD }\end{array}$ & $\begin{array}{c}\text { Total Number } \\
\text { of Cases }\end{array}$ & $\begin{array}{c}\text { Yearly Incidence } \\
\text { Rate } \pm \text { SD }\end{array}$ & $\begin{array}{c}\text { Total Number } \\
\text { of Cases }\end{array}$ & $\begin{array}{c}\text { Yearly Incidence } \\
\text { Rate } \pm \text { SD }\end{array}$ \\
\hline \hline Cervix uteri & 200 & $3 \pm 1$ & 288 & $4 \pm 2$ & 149 & $2 \pm 1$ \\
\hline Gastrointestinal tract & 135 & $2 \pm 1$ & 353 & $5 \pm 1^{1}$ & 69 & $1 \pm 1$ \\
\hline Female breast & 143 & $2 \pm 1$ & 312 & $4 \pm 1^{1}$ & 82 & $1 \pm 1$ \\
\hline Hematological system & 90 & $1 \pm 1$ & 191 & $3 \pm 1^{1}$ & 59 & $1 \pm 1$ \\
\hline Prostate & 44 & $1 \pm 1$ & 377 & $5 \pm 4^{1}$ & 26 & $0 \pm 0$ \\
\hline Head and neck & 59 & $1 \pm 1$ & 138 & $2 \pm 1$ & 49 & $1 \pm 0$ \\
\hline Respiratory tract & 33 & $1 \pm 0$ & 94 & $1 \pm 1$ & 48 & $1 \pm 1$ \\
\hline Liver & 20 & $0 \pm 0$ & 41 & $1 \pm 0$ & 40 & $1 \pm 0$ \\
\hline
\end{tabular}

${ }^{1}$ Significantly different from Hindustani and Javanese in urban areas, as well from Creole, Hindustani, and Javanese in rural areas (Table $\left.\mathbf{3 b}\right)(P<0.05$, ANOVA)

Table 3b. Total Number of Cases and Average Yearly Incidence Rates ( \pm SDs) of Common Cancers in Hindustani, Creole, and Javanese in Rural Areas of Suriname Between 1980 and 2004. Rates are Per 100,000 Rural Residents

\begin{tabular}{|l|c|c|c|c|c|c|}
\hline & \multicolumn{2}{|c|}{ Hindustani } & \multicolumn{2}{c|}{ Creole } & \multicolumn{2}{c|}{ Javanese } \\
\cline { 2 - 7 } & $\begin{array}{c}\text { Total Number } \\
\text { of Cases }\end{array}$ & $\begin{array}{c}\text { Yearly Incidence } \\
\text { Rate } \pm \text { SD }\end{array}$ & $\begin{array}{c}\text { Total Number } \\
\text { of Cases }\end{array}$ & $\begin{array}{c}\text { Yearly Incidence } \\
\text { Rate } \pm \text { SD }\end{array}$ & $\begin{array}{c}\text { Total Number } \\
\text { of Cases } \\
\text { Yearly Incidence } \\
\text { Rate } \pm \text { SD }\end{array}$ \\
\hline \hline Cervix uteri & 84 & $3 \pm 2$ & 48 & $1 \pm 1$ & 64 & $2 \pm 1$ \\
\hline Gastrointestinal tract & 46 & $1 \pm 1$ & 40 & $1 \pm 1$ & 46 & $1 \pm 1$ \\
\hline Female breast & 59 & $2 \pm 1$ & 29 & $1 \pm 1$ & 31 & 29 \\
\hline Hematological system & 31 & $1 \pm 1$ & 37 & $1 \pm 1$ & $1 \pm 1$ \\
\hline Prostate & 8 & $0 \pm 0$ & 61 & $2 \pm 2$ & 12 & $0 \pm 1$ \\
\hline Head and neck & 35 & $1 \pm 1$ & 25 & $1 \pm 1$ & 33 & $1 \pm 1$ \\
\hline Respiratory tract & 3 & $0 \pm 0$ & 12 & $0 \pm 1$ & 29 & $1 \pm 1$ \\
\hline Liver & 8 & $0 \pm 1$ & 10 & $0 \pm 1$ & 35 & $1 \pm 1$ \\
\hline
\end{tabular}

cancer types in urban individuals of 50 years and older - particularly those of the gastrointestinal tract, breast, and prostate - were approximately twice those of their rural counterparts. Once again, cervical cancer, and probably also head and neck, respiratory tract, as well as liver cancer, were the main exception: the incidence rates in urban women of 50 years and older did not differ significantly from those in rural women of the same age group (Tables $\mathbf{4 a}$ and $\mathbf{4 b}$ ).

\section{DISCUSSION}

Making use of data from the national cancer registry of the Republic of Suriname over the period from 1980 through 2004, we obtained in this study strong evidence for the existence of ethnic and age-related differences between the urban and rural areas of that country with respect to the occurrence of cancer. This conclusion is based on the significant differences between both areas regarding the ethnic and age distribution of cancer.

That there were differences between Suriname's urban and rural areas with respect to the occurrence of malignant disease was immediately evident from the approximately twice higher cancer incidence rates in the urban areas when compared to the rural areas. This held true for both cancer overall and for leading malignancies such as those of the gastrointestinal tract, breast, hematological system, and pros- tate, either stratified for gender or not. These findings are in line with previously described geographic trends suggesting that cancer incidence rates are usually higher in densely inhabited, urbanized areas than in less populated, nonmetropolitan areas [4,5].

Such urban-rural variations in cancer incidence might be tentatively explained, at least partially, by the availability of more sophisticated diagnostic services in urban areas when compared to rural areas [10], and/or by the generally higher socioeconomic standing of the former areas when compared to the latter [10]. As a consequence, urban residents would have better access to early detection methods than their rural counterparts, which might result in the identification of more malignancies - particularly of those that are most common in the former group than in the latter. Indeed, from the records consulted for the present survey it could be inferred that there were on average 1.75 times more rural patients presenting with metastatic disease when compared to urban patients in the period covered by this study (data not shown).

These suppositions are supported by an Australian report according to which the degree of remoteness from major health centers had a substantial influence on urban-rural variations in breast cancer incidence, mortality, and five-year survival rates [15]. Furthermore, studies on the effect of rural environment and socioeconomic status on cancer stage at di- 
Table 4a. Total Number of Cases and Average Yearly Incidence Rates ( \pm SDs) of Common Cancers in Age Groups Between 0 and 19 Years, Between 20 and 29 Years, and of 50 Years and Older in Urban Areas of Suriname Between 1980 and 2004. Rates are Per 100,000 Urban Residents

\begin{tabular}{|l|c|c|c|c|c|c|}
\hline & \multicolumn{2}{|c|}{ 0-19 Years } & \multicolumn{2}{|c|}{ 20-49 Years } & \multicolumn{2}{|c|}{ 50+ Years } \\
\cline { 2 - 7 } & $\begin{array}{c}\text { Total Number } \\
\text { of Cases }\end{array}$ & $\begin{array}{c}\text { Yearly Incidence } \\
\text { Rate } \pm \text { SD }\end{array}$ & $\begin{array}{c}\text { Total Number } \\
\text { of Cases }\end{array}$ & $\begin{array}{c}\text { Yearly Incidence } \\
\text { Rate } \pm \text { SD }\end{array}$ & $\begin{array}{c}\text { Total Number } \\
\text { of Cases }\end{array}$ & $\begin{array}{c}\text { Yearly Incidence } \\
\text { Rate } \pm \text { SD }\end{array}$ \\
\hline \hline Cervix uteri & 1 & $0 \pm 0$ & 375 & $6 \pm 2^{1}$ & 438 & $6 \pm 2^{1}$ \\
\hline Gastrointestinal tract & 5 & $0 \pm 0$ & 148 & $2 \pm 1^{1}$ & 569 & $8 \pm 2^{1,2,3}$ \\
\hline Female breast & 3 & $0 \pm 0$ & 220 & $3 \pm 1^{1}$ & 426 & $6 \pm 2^{1,2,3}$ \\
\hline Hematological system & 81 & $1 \pm 1$ & 137 & $2 \pm 1^{1}$ & 191 & $3 \pm 2^{1}$ \\
\hline Prostate & 4 & $0 \pm 0$ & 13 & $0 \pm 0$ & 508 & $7 \pm 5^{1,2,3}$ \\
\hline Head and neck & 16 & $0 \pm 0$ & 74 & $1 \pm 1$ & 225 & $3 \pm 2^{1,2}$ \\
\hline Respiratory tract & 0 & $0 \pm 0$ & 29 & $0 \pm 1$ & 93 & $1 \pm 1$ \\
\hline Liver & 5 & $0 \pm 0$ & 41 & $1 \pm 0$ & 40 \\
\hline
\end{tabular}

${ }^{1}$ Significantly different from $0-19$ years (ANOVA, $P<0.05$ ); ${ }^{2}$ significantly different from $20-49$ years (ANOVA, $P<0.05$ ); ${ }^{3}$ significantly different from '50 years and older' in rural areas (Table 4b) $(P<0.05)$.

Table 4b. Total Number of Cases and Average Yearly Incidence Rates ( \pm SDs) of Common Cancers in Age Groups Between 0 and 19 Years, Between 20 and 29 Years, and of 50 Years And older in Rural Areas of Suriname Between 1980 and 2004 . Rates are Per 100,000 Rural Residents

\begin{tabular}{|c|c|c|c|c|c|c|}
\hline & \multicolumn{2}{|c|}{ 0-19 Years } & \multicolumn{2}{|c|}{ 20-49 Years } & \multicolumn{2}{|c|}{$50+$ Years } \\
\hline & $\begin{array}{c}\text { Total Number } \\
\text { of Cases }\end{array}$ & $\begin{array}{c}\text { Yearly Incidence } \\
\text { Rate } \pm \text { SD }\end{array}$ & $\begin{array}{c}\text { Total Number } \\
\text { of Cases }\end{array}$ & $\begin{array}{c}\text { Yearly Incidence } \\
\text { Rate } \pm \text { SD }\end{array}$ & $\begin{array}{c}\text { Total Number } \\
\text { of Cases }\end{array}$ & $\begin{array}{c}\text { Yearly Incidence } \\
\text { Rate } \pm \text { SD }\end{array}$ \\
\hline Cervix uteri & 1 & $0 \pm 0$ & 167 & $5 \pm 3^{1}$ & 139 & $4 \pm 2^{1}$ \\
\hline Gastrointestinal tract & 2 & $0 \pm 0$ & 39 & $1 \pm 1^{1}$ & 129 & $4 \pm 2^{1.2}$ \\
\hline Female breast & 1 & $0 \pm 0$ & 55 & $2 \pm 1^{1}$ & 73 & $2 \pm 1^{1}$ \\
\hline Hematological system & 34 & $1 \pm 1$ & 38 & $1 \pm 1$ & 61 & $2 \pm 1$ \\
\hline Prostate & 0 & $0 \pm 0$ & 0 & $0 \pm 0$ & 110 & $3 \pm 2^{1,2}$ \\
\hline Head and neck & 7 & $0 \pm 0$ & 30 & $1 \pm 1^{1}$ & 71 & $2 \pm 2^{1,2}$ \\
\hline Respiratory tract & 0 & $0 \pm 0$ & 7 & $0 \pm 0$ & 40 & $1 \pm 1^{1}$ \\
\hline Liver & 4 & $0 \pm 0$ & 13 & $0 \pm 1$ & 50 & $2 \pm 1^{1,2}$ \\
\hline
\end{tabular}

${ }^{\mathrm{i}}$ Significantly different from $0-19$ years $(\mathrm{P}<0.05){ }^{2}$ significantly different from $20-49$ years (ANOVA, $\left.P<0.05\right)$.

agnosis concluded that less privileged rural patients were usually less frequently treated in specialized health care centers and were often much later diagnosed when compared to socioeconomically more fortunate urban residents [15-17].

In addition to disparities with respect to the availability of health care facilities and inequalities regarding socioeconomic status, urban-rural differences in cancer incidence might be attributed to dissimilarities in life-style and behavior. Indeed, the consumption of more 'western' diets and the adaptation of 'western' reproductive behavioral patterns by metropolitan societies have been associated with increased incidence rates of colorectal and prostate cancer, and ovarian and cervical cancer, respectively [18-21]. Obviously, whether these relationships also apply to Suriname must be verified in future studies.

The existence of ethnic differences between the urban and rural areas of Suriname with regards to the distribution of cancer was reflected by the predominance of malignant disease in urban Creole over rural Creole as well as the other ethnic groups in either region. Indeed, incidence rates of cancer overall and of several leading malignancies were at least twice higher in the former group when compared to the latter. These findings are largely in line with previous reports mentioning that about half of the nearly 900 cases of malignant disease in Suriname between 1991 and 1993 were Creole [10], and that incidence rates of most common cancers diagnosed between 1980 and 2000 in that country were 2- to 6-fold higher in Creole than in Hindustani and Javanese [14].

There is no satisfactory explanation why urban Creole might be more prone to develop cancer than the other ethnic groups. However, in a typical 'western' society such as the United States of America, cancer was more frequently seen in African-Americans than in other ethnic groups, overall incidence rates for the former group being 10\%, 50-60\%, and more than twice higher than those for Caucasians, Hispanics and Asian/Pacific Islanders, and American Indians, respectively [22-24]. Of note, the apparent differences in cancer incidence between urban and rural Creole hints that life-style and environmental factors rather than genetic factors might play a role in the epidemiology of (certain) cancer(s) in Suriname.

The results from the 2004-census indicated that individuals of 60 years and older comprised only $4.5 \%$ of the urban popu- 
lation, but $15 \%$ of the rural population of Suriname [11]. Thus, the nearly twice higher cancer incidence in urban individuals of 50 years and older when compared to that in rural people of the same age group noticed in this study, was probably not due to differences in size between the two populations [10]. Furthermore, urban and rural patients presented on average age at the same age (viz. at $10 \pm 2$ and $11 \pm 3,39 \pm 1$ and $39 \pm 1$, and $67 \pm 2$ and $65 \pm 2$ years, respectively, in age groups 0 to 19,20 to 49 , and 50 years and older, respectively (data not shown). This makes it unlikely that the difference between older urban and rural individuals in cancer incidence was because of differences in age distribution between both populations, and as a consequence, because of more urban than rural patients presenting with cancer at an older age. Rather, the abovementioned observation might be attributed to the abovementioned better access to, and better utilization of diagnostic facilities by urban residents with in general a higher socioeconomic status when compared to rural people [10].

The comparable incidence of cervical cancer in urban and rural women of 50 years and older might be ascribed to the lack of effective Papanicolaou screening programs in both areas $[14,25]$.

\section{CONCLUSIONS}

With the exception of cervical cancer as well as other less common malignancies such as head and neck, respiratory tract, and liver cancer, malignant disease, particularly gastrointestinal, breast, hematological and prostate cancer, was more often seen in urban areas than in rural areas, was more common in urban Creole than in other ethnic groups from either region, and was more frequently diagnosed in older urban individuals than in older rural people. These incidence patterns are consistent with the existence of differences between the urban and rural areas of Suriname with respect to the ethnic and age distribution of cancer. These findings may be useful for cancer control, research, and intervention, but they must be verified in comprehensive future studies on the urban-rural distribution of suspected etiologic factors. Furthermore, the relatively high incidence of cervical, gastrointestinal, breast, and prostate cancer indicate a greater need for screening programs and, in the case of cervical cancer, even the institution of vaccination programs.

\section{ACKNOWLEDGEMENTS}

The authors are indebted to R. Bipat, $\mathrm{MD}, \mathrm{PhD}$, and $\mathrm{J}$. Toelsie, MD, PhD, both from the Department of Physiology of the Faculty of Medical Sciences, Anton de Kom University of Suriname, for their help with the statistical analyses.

\section{REFERENCES}

[1] Cox CL. Online exclusive: a model of health behavior to guide studies of childhood cancer survivors. Oncol Nurs Forum 2003; 30: E929 .
[2] Guillem JG, Wood WC, Moley JF, et al. ASCO/SSO review of current role of risk-reducing surgery in common hereditary cancer syndromes. J Clin Oncol 2006; 24: 4642-60.

[3] Walley AJ, Blakemore AI, Froguel P. Genetics of obesity and the prediction of risk for health. Hum Mol Genet 2006; 5: R124-30.

[4] Monroe AC, Ricketts TC, Savitz LA. Cancer in rural versus urban populations: a review. J Rural Health 1992; 8: 212-20.

[5] Schouten LJ, Meijer H, Huveneers JA, Kiemeney LA. Urban-rural differences in cancer incidence in The Netherlands 1989-1991. Int J Epidemiol 1996; 25: 729-36.

[6] Shimizu H, Ross RK, Bernstein L, Yatani R, Henderson BE, Mack TM. Cancers of the prostate and breast among Japanese and white immigrants in Los Angeles County. Br J Cancer 1991; 63: 963-6.

[7] Ziegler RG, Hoover RN, Pike MC, et al. Migration patterns and breast cancer risk in Asian-American women. J Natl Cancer Inst 1993; 85: 1819-27.

[8] Li FP, Pawlish K. Cancers in Asian-Americans and Pacific Islanders: migrant studies. Asian Am Pac Isl J Health 1998; 6: 123-9.

[9] Gaston KE, Kim D, Singh S, Ford OH 3rd, Mahler JL. Racial differences in androgen receptor protein expression in men with clinically localized prostate cancer. J Urol 2003; 170: 990-3.

[10] Pan American Health Organization. Suriname. In: Health in the Americas, volume II. Scientific Publication no. 569. Washington DC: Pan American Health Organization 1998; 470-83.

[11] General Bureau of Statistics. Population statistics. Suriname population census 2003. Preliminary report. Suriname in cijfers: no $208-$ 2003/03. Paramaribo: General Bureau of Statistics; 2003.

[12] Pan American Health Organization, Program on Organization and Management of Health Systems and Services, Division of Health Systems and Services Development. Health systems and services profile of Suriname, $1^{\text {st }}$ ed. Washington DC: Pan American Health Organization; 2002.

[13] World Health Organization. International classification of diseases for oncology, $2^{\text {nd }}$ ed. Geneva: World Health Organization, 2000.

[14] Mans DRA, Mohamedradja RN, Hoeblal ARD, et al. Cancer incidence in Suriname from 1980 through 2000: a descriptive study. Tumori 2003; 89: 368-76.

[15] Liff JM, Chow WH, Greenberg RS. Rural urban differences in stage at diagnosis. Possible relationship to cancer screening. Cancer 1991; 67: 1454-9

[16[ Launoy G, Le Coutour X, Gignoux M, Pottier D, Dugleux G. Influence of rural environment on diagnosis, treatment, and prognosis of colorectal cancer. J Epidemiol Commun Health 1992; 46: 365-7.

[17] Jong K, Smith DP, Yu XQ, Goumas C, O'Connell D, Armstrong BK. Remoteness and cancer incidence, mortality and survival in New South Wales 1992 to 1996. Sydney (Australia): The Cancer Council NSW, 2002.

[18] Trock B, Lanza E, Greenwald P. Dietary fiber, vegetables and colon cancer: critical review and meta-analyses of the epidemiologic evidence. J Natl Cancer Inst 1990; 82: 650-61.

[19] Jasienska G, Thune I, Ellison PT. Energetic factors, ovarian steroids and the risk of breast cancer. Eur J Cancer Prev 9: 2000; 9: 231-9.

[20] Jasienska G. Lifestyle, hormones, and risk of breast cancer. Br Med J 2001; 322: 586-7.

[21] Kolonel LN. Fat, meat, and prostate cancer. Epidemiol Rev 2001; 23: 72-81.

[22] Ghafoor A, Jemal A, Cokkinides V, et al. Cancer statistics for African Americans. CA Cancer J Clin 2002; 52: 326-41.

[23] Jemal A, Murray T, Samuels A, Ghafoor A, Ward E, Thun MJ. Cancer statistics, 2003. CA Cancer J Clin 2003; 53: 5-26.

[24] Parkin DM, Bray F, Ferlay J, Pisani P. Global cancer statistics, 2002 CA Cancer J Clin 2005; 55: 74-108.

[25] Franco EL, Duarte-Franco E, Ferenczy A. Cervical cancer: epidemiology, prevention and the role of human papillomavirus infection. J Canadian Med Assoc 2001; 164: 1017-25. 